\title{
Prevalence and genotype distribution of HPV and cervical pathological results in Sichuan Province, China: a three years surveys prior to mass HPV vaccination
}

Qing Luo ${ }^{1}$, Ni Jiang ${ }^{1}$, Qiaoyuan Wu', Jiaqiang Wang ${ }^{2^{*}}$ and Jialing Zhong ${ }^{2,3^{*}}$

\begin{abstract}
Background: HPV persistent infection is a strong carcinogenic factor that can induce cervical cancer. Investigation of HPV epidemiology and genotype distribution is of great meaning for the development of cervical cancer prevention and control strategies.

Methods: By using PCR-based hybridization gene chip assay, HPV genotype was detected from 14,185 women that came from HEC (Health Examination Center) or OGOC (Obstetrics and Gynecology Outpatient Clinics) between 2015 and 2017 in Sichuan area. The epidemiology and genotype distribution as well as the relationship between HPV infection and histology/cytology abnormalities were analyzed.

Results: The positivity rate of HPV was $23.84 \%$. The HPV-positive rate of OGOC group (37.62\%) was significantly higher than that of HEC group (15.29\%), $p<0.05$. The prevalence of HPV reached peak at age $41-50(5.86 \%)$ in HEC group, but at age 21-30 (14.74\%) in OGOC group. Of all the HPV positive women, single genotype infection was the most common form in both HEC and OGOC group (62.06\% in total screening population, $74.36 \%$ in HEC group and $54.01 \%$ in OGOC group). Three most prevalent HPV types were HPV-52 (5.02\%), 58 (3.61\%), and 16 (3.24\%) in total screening population. Of all the HPV positive women, the top three types were HPV-52 (20.93\%), CP8304 (15.32\%), and 58 (14.42\%) in HEC group, while were HPV-52 (21.14\%), 16 (16.34\%), and 58 (15.61\%) in OGOC group. HPV 52/16/58 accounted for $41.84 \%$ of cytology and $56.52 \%$ of histological abnormalities.

Conclusions: Women in Sichuan area were facing the great threat of HPV infection, especially the women aged between $21 \sim 30$ or $41-50$ years old. The priority HPV types were HPV 52, 58, and 16 in OGOC group, while were HPV 52, CP8304, and 58 in HEC group. HPV 52/16/58 accounted for the majority of cytology and histological abnormalities. Our analysis was found to be valuable for providing a scientific basis for the prevention and control strategies of cervical cancer in Sichuan area.
\end{abstract}

Keywords: Human papillomavirus, Genotype distribution, Sichuan area, HPV vaccination

\footnotetext{
*Correspondence: 364017861@qq.com; zhongjialing@med.uestc.edu.cn

${ }^{2}$ Department of Laboratory Medicine, Sichuan Academy of Medical Sciences

\& Sichuan Provincial People's Hospital, No. 32, West Second Section First Ring Rd., Chengdu 610072, Sichuan, China

Full list of author information is available at the end of the article
}

(C) The Author(s). 2020 Open Access This article is licensed under a Creative Commons Attribution 4.0 International License, which permits use, sharing, adaptation, distribution and reproduction in any medium or format, as long as you give appropriate credit to the original author(s) and the source, provide a link to the Creative Commons licence, and indicate if changes were made. The images or other third party material in this article are included in the article's Creative Commons licence, unless indicated otherwise in a credit line to the material. If material is not included in the article's Creative Commons licence and your intended use is not permitted by statutory regulation or exceeds the permitted use, you will need to obtain permission directly from the copyright holder. To view a copy of this licence, visit http://creativecommons.org/licenses/by/4.0/ The Creative Commons Public Domain Dedication waiver (http://creativecommons.org/publicdomain/zero/1.0/) applies to the data made available in this article, unless otherwise stated in a credit line to the data. 


\section{Background}

Cervical cancer is the fourth most common cancer and the fourth leading cause of cancer death for women, with an estimated 570, 000 case and 311,000 deaths in 2018 worldwide, which is a serious threat to female health, especially in developing countries [1]. As the most populous developing country, China has 98,900 new cases of cervical cancer and 30,500 cervical cancerrelated deaths in 2015 [2]. Thus, there is a heavy disease burden of cervical cancer in china.

Human papillomaviruses (HPVs) are non-enveloped, double-stranded circular DNA viruses. To date, over 170 types of HPV have been identified, of which 40 infect the genital tract. Generally, HPVs could be divided into low-risk categories (e.g. HPV 6, 11, 42, 43, 44, CP8304) which were mainly found in the genital warts, and highrisk categories (e.g. HPV 16, 18, 31, 33, 35, 39, 45, 51, $52,53,56,58,59,66$ and 68 ),the persistent infection of which has been recognized as a strong carcinogenic factor to induce cervical cancer $[3,4]$. Because of the huge difference regarding the ability to induce cervical cancer, it was worthwhile to investigate HPV DNA genotype to improve the effect of cervical cancer screening.

HPV vaccines have showed a great potential on the prevention of cervical cancer. The prophylactic injection of HPV vaccine can decline vaccine-type HPV infection and substantially lead to reductions in HPV-associated cancers [5]. However, the vaccines showed prominently type-restricted prophylactic efficacy. They merely induced immunity specific to certain HPV genotypes, and were unable to fend off other genotypes of the virus [4]. Studies also demonstrated that the distribution of HPV genotypes differed considerably both geographically and among populations. Therefore, to investigate the epidemiology and genotype distribution of HPV in a certain population was important for developing HPV vaccine strategy in this area [6].

Sichuan, a province in southwestern China, has the fourth largest population in the country, with a permanent population of 83.41 million in 2018(data from National Bureau of Statistics of China, http://www.stats. gov.cn/). Several studies aimed to investigate the epidemiology and genotype distribution of HPV in this area recent years, however, the results varied a lot [7-12].

In this study, in order to get a more accurate and reliable data, we audited large-scale retrospective data on cervical HPV testing among women that attended Health Examination Center (HEC) and obstetrics and gynecology outpatient clinics (OGOC) during 20152017. We also assessed the relationship between typespecific infection of HPV and the histology/cytology triage, Our study might provide a scientific basis for the prevention and control strategies of cervical cancer in Sichuan area.

\section{Methods}

\section{Study population and include criteria}

A total of 14,185 women who participated in HPV screening in HEC or OGOC of Sichuan People's Hospital were included from 2015 to 2017. The participants were enrolled according to the following selection criteria: (1) was mentally and physically competent; (2) was sexually active women of any age; (3) was willing to undergo HPV testing. The age of the patients ranged from 14 to 78 years old with an average of $39.93 \pm 10.38$ years.

\section{Cervical sample collection}

Samples exfoliated cervical cells were collected by using plastic cervical swabs. Each plastic swab was mixed well with $1 \mathrm{ml}$ of specimen transport medium (Chaozhou Hybribio Biotechnology Limited Corporation, China) and store immediately at $4{ }^{\circ} \mathrm{C}$, and finally sent to our clinical laboratory within 1 day for HPV analysis.

\section{HPV DNA extraction and genotyping}

HPV DNA extraction and genotyping DNA was performed by using Alkaline Lysis Method Kits (Chaozhou Hybribio Biotechnology Limited Corporation, China) and HPV GenoArray Test kit (Chaozhou Hybribio Biotechnology Limited Corporation, China) according to the manufacturer's protocol [13, 14] The GenoArray could identify $15 \mathrm{HR}-\mathrm{HPV}$ (high-risk HPV) types (16, $18,31,33,35,39,45,51,52,53,56,58,59,66$ and 68) and 6 LR-HPV (low-risk HPV) types (6, 11, 42, 43, 44 and CP8304 in Chinese population). The final results were detected by colorimetric change on the GenoArray under direct visualization.

\section{Thin prep liquid-based cytology test}

For cytology test, cervical slides were prepared using Liquid-PREP $^{\text {тм }}$ System (LGM International, USA). The slides were evaluated for cervical cytology by two academic cyto-pathologists of Sichuan Provincial People's Hospital. Cytological classifications of disease grade were made in conformity to the Bethesda 2001 criteria, including negative of intraepithelial lesion or malignancy (NILM), atypical squamous cells of undetermined significance (ASCUS), atypical gland cell (AGC),low-grade squamous intraepithelial lesion (LSIL), high-grade squamous intra epithelial lesion (HSIL) and invasive cervical cancer (ICC).

\section{Histology diagnosis}

For cervical biopsies, Digital Electronic Colposcope (Olympus Company, Japan) was used by specially trained physicians to perform the cervical biopsy tissue collection. The histology results were obtained by two academic Gynecology doctors of Sichuan Provincial 
People's Hospital. A diagnosis was assigned to each case, as having NO Lesion, cervical intraepithelial neoplasia grade 1 (CIN 1), CIN 2, CIN 3, cervical cancer (CA).

\section{Statistical analysis}

All statistical analyses were performed using SPSS 22.0 software (SPSS Inc., Chicago, IL, USA). Typespecific prevalence of HPV infection and their exact binomial 95\% confidence intervals (CI) were calculated. Pearson's $x^{2}$ test was performed to evaluate the significance of differences between designated groups. All analyses were two-sided and interpreted as being significant at $p<0.05$.

\section{Results}

Prevalence of HPV infection in HEC and OGOC group

Overall, 14,185 women were included in this study. Among them, 3382 were HPV positive, account for $23.84 \%$. Among the 14,185 women, 8751 came from HEC, and 5434 came from OGOC. The HPV-positive rate of OGOC group (37.62\%) was significantly higher than that of HEC group (15.29\%), $p<0.05$ (Table 1).

\section{Prevalence of HPV grouped by age in study population}

All the participants were divided into seven groups according to their age ( $\leq 20$ years, $21-30$ years, $31-40$ years, $41-50$ years, $51-60$ years, $61-70$ years and $\geq 71$ years). The prevalence of HPV reached a peak at 21-30 years and $41-50$ years, with a positive rate of 6.70 and $6.42 \%$, respectively. Specifically, the prevalence of HPV reached peak at $41-50$ years group $(5.86 \%)$ in HEC group, but at 21-30 years group (14.74\%) in OGOC group (Table 1, supplementary Fig. 1).

\section{Prevalence of HPV single and multiple HPV genotypes infection}

For all the HPV positive women, single genotype infection was the most $(62.06 \%$ in total group, $74.36 \%$ in
HEC group and $54.01 \%$ in OGOC group). Among the multiple infection cases, double genotype infection was the most, and the infection rate decreased significantly as the number of infected genotypes increased (Table 2). OGOC group showed a significantly higher prevalence rate of multiple genotype infection than HEC group $(p<$ $0.05)$.

\section{Prevalence of HPV genotypes in HPV-positive population}

Among the 21 genotypes of HPV that can be identified by our GenoArray, there were 15 high-risk types (HPV16, 18, 31, 33, 35, 39, 45, 51, 52, 53, 56, 58, 59, 66, 68) and 6 low-risk types $(6,11,42,43,44$, CP8304). In our study, the top three prevalent HPV types were HPV$52(5.02 \%, 712 / 14184), 58(3.61 \%, 512 / 14184)$, and 16 $(3.24 \%, 460 / 14185)$ in total screening population, which followed by CP8304 (3.12\%, 443/14185) and 53(2.89\%, 410/14184). As shown in Table 3, among the HPV positive population, the genotypes of infected HPV varied in different groups. In HEC group, the top three were HPV-52 (20.93\%), CP8304 (15.32\%), 58 (14.42\%), followed by $53(13.75 \%)$ and $16(9.42 \%)$. While in OGOC group, the top three were HPV-52 (21.14\%), 16 (16.34\%), 58 (15.61\%), followed by CP8304 (11.63\%) and 53(11.06\%). The prevalence of HPV 16, 18, 6, 11 genotype was significantly higher in OGOC group than that in HEC group. Interestingly, the prevalence of HPV 53 and CP8304 was significantly higher in HEC group than that in OGOC group.

\section{Distribution of HPV genotypes according to cytology abnormalities}

Figure 1 described the process by which we obtained our final results of cytology and histological abnormalities. Among the 3382 HPV positive women, 2414 were performed Thinprep cytologic test (TCT), and 171 women have been identified to be cytology abnormalities, accounting for $7.08 \%$. The distribution of HPV genotypes

Table 1 Prevalence of HPV infection in different age groups

\begin{tabular}{|c|c|c|c|c|c|c|c|c|c|c|c|c|}
\hline \multirow{3}{*}{$\begin{array}{l}\text { Age } \\
\text { Group } \\
\text { (Year) }\end{array}$} & \multicolumn{6}{|c|}{ Total case } & \multicolumn{6}{|c|}{ HPV positive cases } \\
\hline & \multicolumn{2}{|l|}{ HEC } & \multicolumn{2}{|l|}{ OGOC } & \multicolumn{2}{|l|}{ Total } & \multicolumn{2}{|l|}{$\mathrm{HEC}$} & \multicolumn{2}{|c|}{$\mathrm{OGOC}$} & \multicolumn{2}{|l|}{ Total } \\
\hline & $n$ & $\%^{\mathrm{a}}$ & $n$ & $\%^{a}$ & $n$ & $\%^{a}$ & $n$ & $\%^{b}$ & $n$ & $\%^{b}$ & $n$ & $\%^{b}$ \\
\hline$\leq 20$ & 2 & 0.02 & 149 & 2.74 & 151 & 1.06 & 1 & 0.01 & 86 & 1.58 & 87 & 0.61 \\
\hline $21-30$ & 902 & 10.31 & 2111 & 38.85 & 3013 & 21.24 & 149 & 1.70 & 801 & 14.74 & 950 & 6.70 \\
\hline $31-40$ & 2722 & 31.11 & 1368 & 25.17 & 4090 & 28.83 & 404 & 4.62 & 462 & 8.50 & 866 & 6.11 \\
\hline $41-50$ & 3552 & 40.59 & 1201 & 22.10 & 4753 & 33.51 & 513 & 5.86 & 397 & 7.31 & 910 & 6.42 \\
\hline $51-60$ & 1262 & 14.42 & 457 & 8.41 & 1719 & 12.12 & 220 & 2.51 & 215 & 3.96 & 435 & 3.07 \\
\hline $61-70$ & 274 & 3.13 & 129 & 2.37 & 403 & 2.84 & 47 & 0.54 & 75 & 1.38 & 122 & 0.86 \\
\hline$\geq 71$ & 37 & 0.42 & 19 & 0.35 & 56 & 0.39 & 4 & 0.05 & 8 & 0.15 & 12 & 0.08 \\
\hline Total & 8751 & 100.00 & 5434 & 100.00 & 14,185 & 100.00 & 1338 & 15.29 & 2044 & 37.62 & 3382 & 23.84 \\
\hline
\end{tabular}

a: Percentage of each age group in HEC/OGOC /Total group

${ }^{b}$ : Percentage of HPV positive cases in each age group in HEC/OGOC/Total group 
Table 2 Prevalence of HPV single/multiple infection in HEC and OGOC group

\begin{tabular}{|c|c|c|c|c|c|c|}
\hline \multirow{2}{*}{$\begin{array}{l}\text { Prevalence of HPV } \\
\text { infection }\end{array}$} & \multicolumn{2}{|c|}{ Total HPV ${ }^{+}$} & \multicolumn{2}{|c|}{$\mathrm{HEC} \mathrm{HPV}^{+}$} & \multicolumn{2}{|c|}{${\mathrm{OGOC} \mathrm{HPV}^{+}}^{+}$} \\
\hline & $n$ & $\%^{a}$ & $n$ & $\%^{a}$ & $n$ & $\%^{a}$ \\
\hline Single Infection & 2099 & 62.06 & 995 & 74.36 & 1104 & 54.01 \\
\hline Mutlple Infection & 1283 & 37.94 & 343 & 25.64 & 940 & 45.99 \\
\hline Double Infection & 903 & 26.70 & 267 & 19.96 & 636 & 31.12 \\
\hline Triple Infection & 266 & 7.87 & 64 & 4.78 & 202 & 9.88 \\
\hline Quadruple Infection & 76 & 2.25 & 11 & 0.82 & 65 & 3.18 \\
\hline Quintet Infection & 22 & 0.65 & 0 & 0.00 & 22 & 1.08 \\
\hline Sextuple Infection & 10 & 0.30 & 1 & 0.07 & 9 & 0.44 \\
\hline Septuple Infection & 6 & 0.18 & 0 & 0.00 & 6 & 0.29 \\
\hline Total Infection & 3382 & 100.00 & 1338 & 100.00 & 2044 & 100.00 \\
\hline
\end{tabular}

a: Percentage of each infection form in HPV positive women of Total/HEC/OGOC group

in cytology abnormalities was showed in Table 4. Singlegenotype infection was the main infection mode in ASCUS (77/125, 61.60\%), LSIL (22/37, 59.46\%) and HSIL $(1 / 1,100 \%)$ group. As for AGC group, the singlegenotype infection rate was $50 \%(4 / 4)$. The most common infected genotype was HPV 52 (29.60\%) in ASCUS group, HPV 66 (21.62\%) in LSIL group, HPV 58 (100\%) in both HSIL and AGC group. Prevalence of high-risk HPV is $81.41,88.57$ and $100 \%$ in ASCUS, LSIL and HSIL, respectively. The top infected genotype was HPV52 in ASCUS group, HPV 66 in LSIL group, and HPV 58 in HSIL group.

\section{Distribution of HPV genotypes according to histological abnormalities}

Among the 3382 HPV positive women, 318 were performed cervical biopsy, and 59 women were identified to be histological abnormalities (accounting for 18.55\%). The single-genotype infection was still the main infection mode in CIN I (21/37, 56.76\%), CINII (13/17, 76.47\%), CIN III $(2 / 2,100 \%)$ and CA (2/3, 66.67\%) group. The most common genotypes are HPV 58 (35.14\%), 52(27.03\%), 16(21.62\%) in CIN I group, HPV 16 (70.59\%), 52/33(23.52, 23.52\%), 51/39(11.76,11.76\%) in CINIIgroup, HPV 58/16 (50, 50\%) in CIN IIIand HPV16/18/51/58 (25.00, 25.00, 25.00, 25.00\%) in CA group (Table 5).

\section{Prevalence of HPV infection change by year}

In order to inspect the infection of HPV in the past 3 years, we analyzed the data by years. As shown in Fig. 2, there was a mild uptick in the number of people who received HPV genotyping test, especially in the OGOC group. Although the HPV infection rate of OGOC group reached a peak in 2016, there was no significant change of that for total population during 2015 to 2017.

\section{Discussion}

The HPV infection prevalence varies considerably from geographies to populations. Globally, the highest HPV infection rate was in Sub-Saharan (25.6\%), followed by South America (14.3\%), Asia (8.7\%), and Europe (5.2\%) [6]. Even within one country, the HPV infection rate varied. It was $28.4 \%$ in northeast China, $20.16 \%$ in south China and $14.2 \%$ in northwest China [15-17]. The prevalence of neighboring southwest provinces was $26.2 \%$ in Chonqing, $16.95 \%$ in Guizhou, $12.9 \%$ in Yunnan [18-20]. Sichuan was the fourth largest population province located in southwestern China. Several studies have investigated the HPV epidemiology. However the results varied, the prevalence rate ranged from 10.15 to $31.3 \%$ [7-12]. Despite these studies, to the best of our knowledge, there was no previous study arising from large samples collected over a long period of time on both low risk and high risk HPV genotype distribution among both women that attended OGOC and HEC. In order to provide a more scientific basis for the prevention and control strategies of cervical cancer in Sichuan area, we performed this analysis. In our study, the HPV infection prevalence of the total population was $23.84 \%$, which was basically consistent with the result of $\mathrm{Li}$ et al. (24.1\%) [12]. After further analyzing, we found HPV infection prevalence in HEC group (15.29\%) was significantly lower than that in OGOC group (37.62\%). The prevalence of HPV infection of HEC population in our study was higher than that of $\mathrm{He}$ et al.'s research (12.6\%) [9], which might due to that $\mathrm{He}$ et al.'s research calculated the high-risk HPV infection of OGOC population only. For OGOC population, our prevalence rate was slightly higher than that of Zhu et al.'s study (32.0\%) [11]. Compared to other province of China, our HPV infection prevalence of HEC group was lower than that in Guangdong (17.25\%) and Zhejiang (19.5\%) [15, 21]. Our HPV infection prevalence of OGOC group was higher than that in Hubei (17.68\%), Guangdong (20.16\%) and Zhejiang (22.3\%), but lower than that of Fujian (38.3\%) $[15,22-24]$. These might mainly be attributed to geographical variation. Thus, according to our data, women in Sichuan area were facing the great threat of HPV infection, especially the women undergoing gynecological clinical symptoms.

Considering the age of infected women, we found prevalence of HPV infection reached a peak at 21-30 years and 41-50 years group. This double-peak result was also found in other area of China, such as Hangzhou and Chongqing [20, 23]. However, after dividing the population into HEC or OGOC groups, we found the prevalence of HPV reached peak at 41-50 years group in HEC group, but at 21-30 years group in OGOC group. 
A possible explanation was young women were more sexually active. For example, they might have higher frequency of sex and more different sex partners. Besides, their immune systems were not sensitive to HPV infection, which resulted in the high infection rate in $21-30$ years group. The high

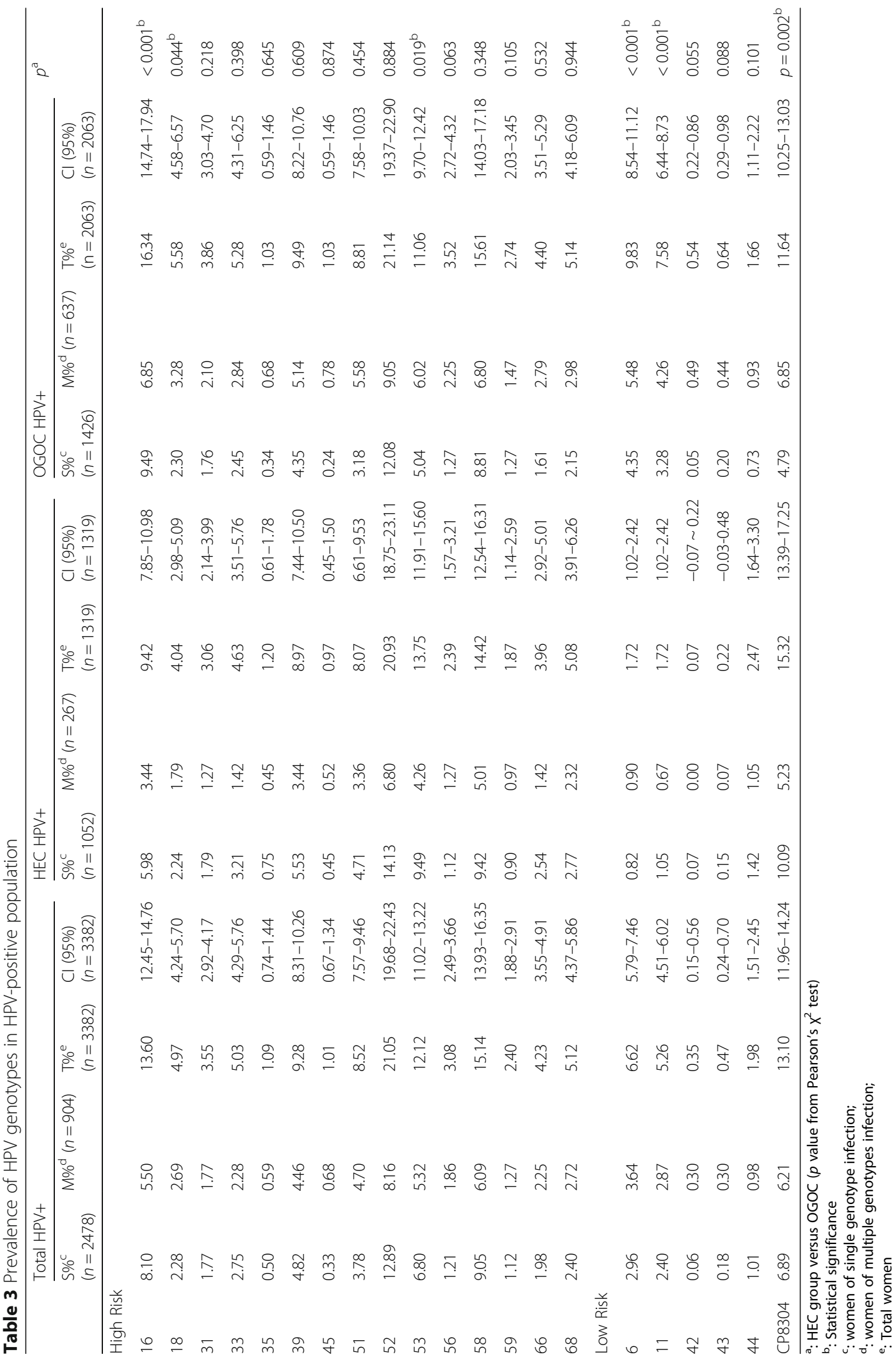




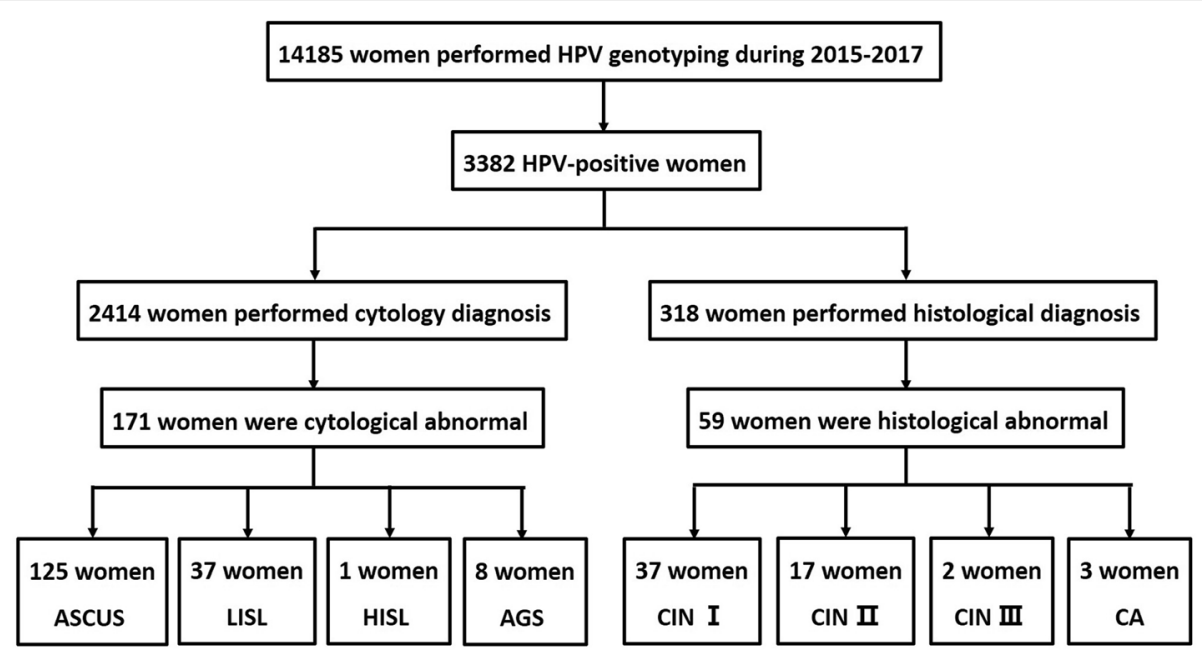

Fig. 1 Flow chart of cytology and histological abnormalities samples

infection rate of 41-50 years group might due to reduced immune functions [23, 25, 26]. According to our data, women of $21-30$ or $41-50$ years old should pay more attention to HPV infection.

In our study, among the HPV positive population, we demonstrated that single genotype infection was the most, which were basically consistent with data of Tao et al. [27].

According to HPV prevalence survey, the most prevalent genotype worldwide was HPV 16 (2.41\%), followed by HPV $58(1.25 \%)$ and 31(1.07\%) [6]. However several studies have demonstrated that HPV16, 52, 58 were the major infection genotypes in China [15, 22-24]. In our study, the top three prevalent HPV genotypes were HPV $52(5.02 \%), 58(3.61 \%)$, and $16(3.24 \%)$ in the total screening population. Among the HPV positive women, HPV 52 was the most prevalent genotype in Sichuan area, which was consist with the data of $\mathrm{Li}$ et al. [12]. And this pattern was also showed in Yunnan and Guizhou Province. However, in a previous study by Sichuan, HPV 16 was identified to be the top prevalent genotype (19.4\%) [27]. This might due to the bias of sample size and different survey period. Even though there were some discrepant results, the most prevalent genotype in Sichuan area were HPV 58, 16, 52. Among the low-risk HPV genotypes, HPV CP8304 was the most prevalent genotype in both HEC and OGOC group, which was consistent with Le et al.'s research [15]. In OGOC group, HPV 16, 18, 6, 11 genotype prevalence were significantly higher than in HEC group, while HPV 53 and CP8304 genotype prevalence were significantly lower than in HEC group. A possible explanation for the different prevalence of HPV 6 and HPV 11 in HEC and OGOC group might be that the infection of these genotypes were more likely to cause genital warts and made patients went to hospital for treatment. However, the reasons for these differences HPV prevalence between OGOG and HEC group remain unknown and should be investigated. In general, this information was meaningful for generating strategies for both cervical cancer screening and vaccine exploitation.

Persistent infection of high-risk HPV was a strong carcinogenic factor to induce cervical cancer. In present study, the prevalence of high-risk HPV was 81.41, 88.57, and $100 \%$ in ASCUS, LSIL and HSIL, respectively. The top genotypes were HPV52 in ASCUS, HPV 66 in LSIL, and HPV 58 in HSIL. HPV 52, 58, 16 accounted for $41.84 \%$ of cytology abnormalities. These results were consistent with the data of $\mathrm{He}$ et al., except for the HPV 66, 39 in LSIL, which may due to the bias of sample size [9].

Among histological abnormalities, the prevalence of high-risk HPV were 89.83, 96.30, 100, and $100 \%$ in CIN I, CINII, CIN III and CA. The top three genotypes were HPV 58 (21.62\%), 52(27.03\%), and 16(21.62\%) in CIN I group, HPV 16 (70.59\%), 52/33(23.52,23.52\%), 51/ $39(11.76,11.76 \%)$ in CINIIgroup, HPV 58/16 (50,50\%) in CIN III and HPV16/18/51/58 (25.00,25.00,25.00,25.00\%) in CA group. HPV 52, 58, 16 accounted for $56.52 \%$ of histological abnormalities, which was consistent with several studies that investigated the relationship between HPV genotype and histological abnormalities in Sichuan area. These studies demonstrated that HPV 16, 58, 52 infection accounted for a large percentage of histological abnormalities [10, 11, 27-29].

HPV vaccine was introduced to China in 2017. The bivalent vaccine (Cervarix, targeted at HPV16/18) was available since August 2017, and the quadrivalent vaccine (Gardasil, targeted at HPV6/11/16/18) was available since December 2017 in Sichuan province [12]. Thus, 


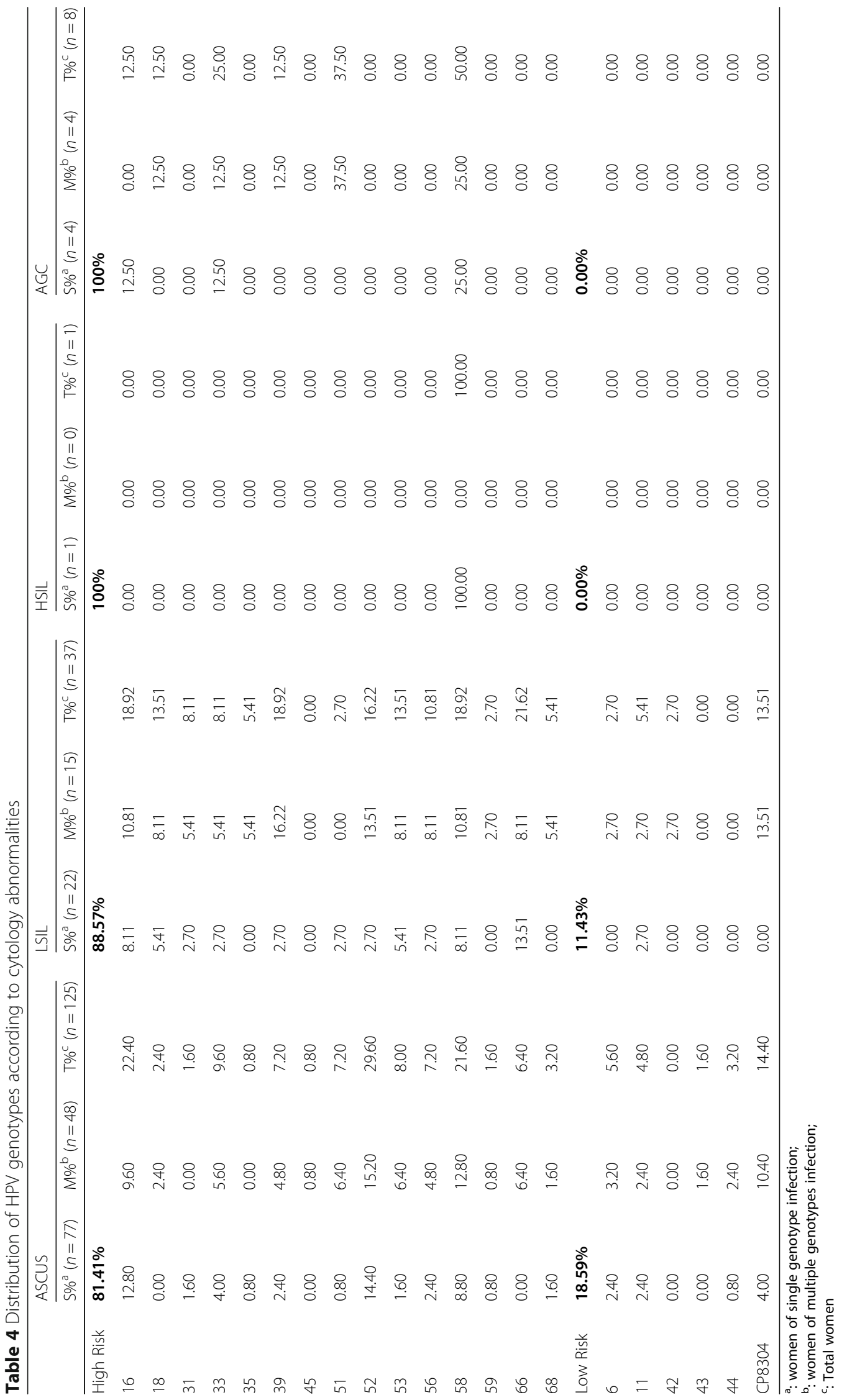


Table 5 Distribution of HPV genotypes according to histological abnormalities

\begin{tabular}{|c|c|c|c|c|c|c|c|c|c|c|c|c|}
\hline & \multicolumn{3}{|l|}{ CIN I } & \multicolumn{3}{|l|}{ CIN II } & \multicolumn{3}{|l|}{ CIN III } & \multicolumn{3}{|l|}{$C A$} \\
\hline & $\begin{array}{l}\text { S\% } \\
(\boldsymbol{n}=21)\end{array}$ & $\begin{array}{l}M \%^{\mathbf{b}} \\
(\boldsymbol{n}=16)\end{array}$ & $\begin{array}{l}\text { T\% } \\
(n=37)\end{array}$ & $\begin{array}{l}\text { S\% } \\
(\boldsymbol{n}=13)\end{array}$ & $\begin{array}{l}\mathrm{M} \%^{\mathbf{b}} \\
(\boldsymbol{n}=4)\end{array}$ & $\begin{array}{l}\text { T\% } \\
(\boldsymbol{n}=17)\end{array}$ & $\begin{array}{l}\mathbf{S} \%^{\mathbf{a}} \\
(\boldsymbol{n}=2)\end{array}$ & $\begin{array}{l}\mathrm{M} \%^{\mathbf{b}} \\
(\boldsymbol{n}=0)\end{array}$ & $\begin{array}{l}\text { T\% } \\
(\boldsymbol{n}=2)\end{array}$ & $\begin{array}{l}\mathrm{S} \%^{\mathbf{a}} \\
(\boldsymbol{n}=2)\end{array}$ & $\begin{array}{l}\mathrm{M} \%{ }^{\mathbf{b}} \\
(\boldsymbol{n}=1)\end{array}$ & $\begin{array}{l}\mathrm{T} \% \%^{\mathbf{c}} \\
(\boldsymbol{n}=3)\end{array}$ \\
\hline High Risk & $89.83 \%$ & & & $96.30 \%$ & & & $100 \%$ & & & $100 \%$ & & \\
\hline 16 & 10.81 & 10.81 & 21.62 & 52.94 & 17.65 & 70.59 & 50.00 & 0.00 & 50.00 & 25.00 & 0.00 & 25.00 \\
\hline 18 & 0.00 & 5.41 & 5.41 & 5.88 & 0.00 & 5.88 & 0.00 & 0.00 & 0.00 & 0.00 & 25.00 & 25.00 \\
\hline 31 & 0.00 & 2.70 & 2.70 & 0.00 & 0.00 & 0.00 & 0.00 & 0.00 & 0.00 & 0.00 & 0.00 & 0.00 \\
\hline 33 & 5.41 & 0.00 & 5.41 & 11.76 & 11.76 & 23.53 & 0.00 & 0.00 & 0.00 & 0.00 & 0.00 & 0.00 \\
\hline 35 & 0.00 & 2.70 & 2.70 & 0.00 & 0.00 & 0.00 & 0.00 & 0.00 & 0.00 & 0.00 & 0.00 & 0.00 \\
\hline 39 & 2.70 & 8.11 & 10.81 & 0.00 & 11.76 & 11.76 & 0.00 & 0.00 & 0.00 & 0.00 & 0.00 & 0.00 \\
\hline 45 & 0.00 & 0.00 & 0.00 & 0.00 & 0.00 & 0.00 & 0.00 & 0.00 & 0.00 & 0.00 & 0.00 & 0.00 \\
\hline 51 & 2.70 & 2.70 & 5.41 & 0.00 & 11.76 & 11.76 & 0.00 & 0.00 & 0.00 & 0.00 & 25.00 & 25.00 \\
\hline 52 & 13.51 & 13.51 & 27.03 & 5.88 & 17.65 & 23.53 & 0.00 & 0.00 & 0.00 & 0.00 & 0.00 & 0.00 \\
\hline 53 & 0.00 & 8.11 & 8.11 & 0.00 & 0.00 & 0.00 & 0.00 & 0.00 & 0.00 & 0.00 & 0.00 & 0.00 \\
\hline 56 & 2.70 & 8.11 & 10.81 & 0.00 & 0.00 & 0.00 & 0.00 & 0.00 & 0.00 & 0.00 & 0.00 & 0.00 \\
\hline 58 & 18.92 & 16.22 & 35.14 & 0.00 & 5.88 & 5.88 & 50.00 & 0.00 & 50.00 & 25.00 & 0.00 & 25.00 \\
\hline 59 & 0.00 & 2.70 & 2.70 & 0.00 & 0.00 & 0.00 & 0.00 & 0.00 & 0.00 & 0.00 & 0.00 & 0.00 \\
\hline 66 & 0.00 & 2.70 & 2.70 & 0.00 & 0.00 & 0.00 & 0.00 & 0.00 & 0.00 & 0.00 & 0.00 & 0.00 \\
\hline 68 & 0.00 & 2.70 & 2.70 & 0.00 & 0.00 & 0.00 & 0.00 & 0.00 & 0.00 & 0.00 & 0.00 & 0.00 \\
\hline Low Risk & $10.17 \%$ & & & $3.70 \%$ & & & $0.00 \%$ & & $0.00 \%$ & & & \\
\hline 6 & 0.00 & 0.00 & 0.00 & 0.00 & 5.88 & 5.88 & 0.00 & 0.00 & 0.00 & 0.00 & 0.00 & 0.00 \\
\hline 11 & 0.00 & 2.70 & 2.70 & 0.00 & 0.00 & 0.00 & 0.00 & 0.00 & 0.00 & 0.00 & 0.00 & 0.00 \\
\hline 42 & 0.00 & 0.00 & 0.00 & 0.00 & 0.00 & 0.00 & 0.00 & 0.00 & 0.00 & 0.00 & 0.00 & 0.00 \\
\hline 43 & 0.00 & 2.70 & 2.70 & 0.00 & 0.00 & 0.00 & 0.00 & 0.00 & 0.00 & 0.00 & 0.00 & 0.00 \\
\hline 44 & 0.00 & 2.70 & 2.70 & 0.00 & 0.00 & 0.00 & 0.00 & 0.00 & 0.00 & 0.00 & 0.00 & 0.00 \\
\hline CP8304 & 0.00 & 8.11 & 8.11 & 0.00 & 0.00 & 0.00 & 0.00 & 0.00 & 0.00 & 0.00 & 0.00 & 0.00 \\
\hline
\end{tabular}

a: women of single genotype infection;

b: women of multiple genotypes infection;

c: Total women
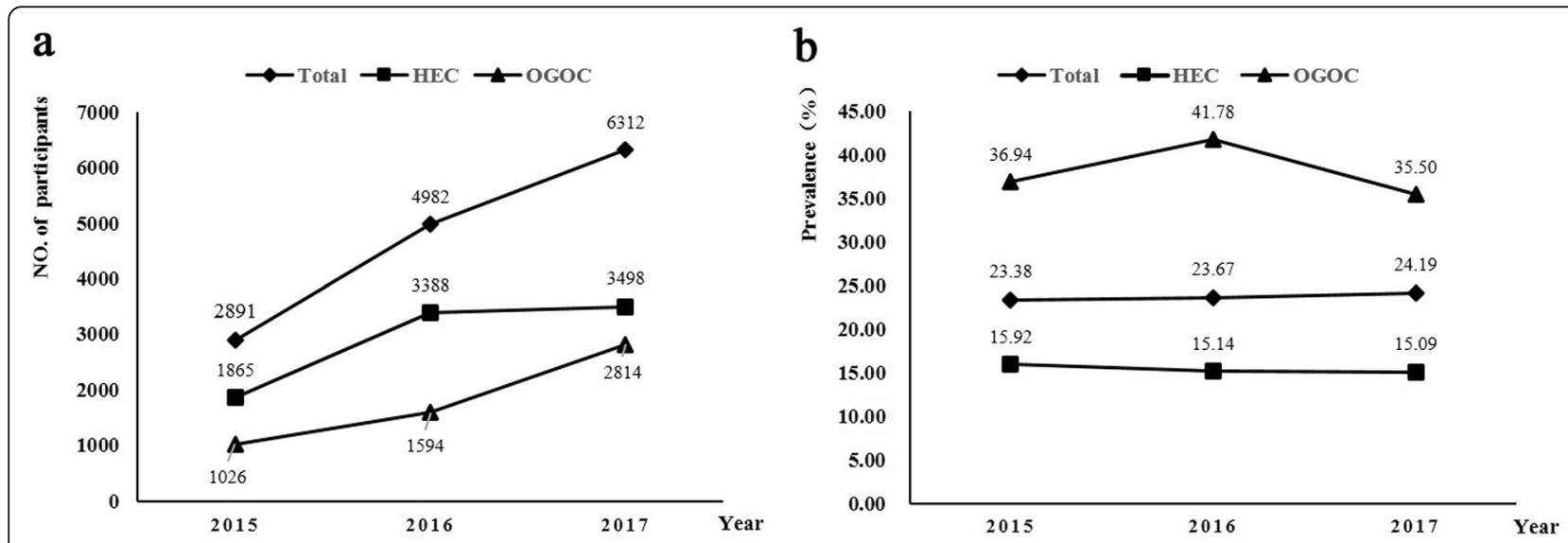

Fig. 2 Prevalence of HPV infection change by year. (a: Number of women participate HPV genotyping test by year, b: Prevalence of HPV by year) 
our study was a survey before the mass use of HPV vaccine in Sichuan area. According to our study, these two kinds of vaccine cannot provide enough protection because of the high prevalent of HPV 52, 58 genotypes. Therefore, the nine-valent vaccine (Gardasil, targeted at HPV6/11/16/18/31/33/45/52/58) was more suitable for women of Sichuan province, which should be introduced as soon as possible. In addition, according to He et al.'s study, at least half women in western China were willing to take the HPV vaccine, because it would be beneficial to the prevention and treatment of HPV infection [30].

There were several limitations in this study. One was the absence of data from other areas in Sichuan province, which meant these results might not represent all women in Sichuan. Second, detailed information of population (e.g. number of sexual partners, smoking habits, etc.) was not available for us to evaluate the effect of these characteristics on the prevalence of HPV infection. Third, we have not performed the analysis on the genotypes distribution of per age group, which limited the understanding on the prevalence of HPV at every age stage. Last, the case of cervical cytology or histology abnormalities was limited. Therefore, larger and prospective studies about the mechanism are needed to validate our findings.

\section{Conclusions}

Women in Sichuan area are facing great threat of HPV infection, especially the women undergoing gynecological clinical symptoms. Women with ages of $21 \sim 30$ or $41 \sim 50$ years old should pay more attention to HPV infection. The most prevalent genotypes in HEC group are HPV 52/CP8303/58, while in OGOC group are HPV 52/58/16. HPV 52/16/58 accounte for the majority of cytology and histological abnormalities. These data could provide a scientific basis for the prevention and control strategies of cervical cancer in Sichuan area.

\section{Supplementary information}

Supplementary information accompanies this paper at https://doi.org/10. 1186/s12985-020-01366-2.

Additional file 1: Supplementary Figure 1. Prevalence of HPV

grouped by age in study population.

\footnotetext{
Abbreviations

AGC: Atypical gland cells; ASCUS: Atypical squamous cells of undetermined significance; Cl: Confidence intervals; CIN: Cervical intraepithelial neoplasia; DNA: DeoxyriboNucleic Acid; HEC: Health Examination Center; HPV: Human papillomavirus; HR-HPV: High-risk HPV; HSIL: High-grade squamous intra epithelial lesion; ICC: Invasive cervical cancer; LR-HPV: Low-risk HPV; LSIL: Low-grade squamous intraepithelial lesion; NILM: Negative of intraepithelial lesion or malignancy; OGOC: Obstetrics and gynecology outpatient clinics; PCR: Polymerase chain reaction; TCT: Thinprep cytologic test
}

\section{Acknowledgements}

We thank Xiangqin Liu, Juan Long, Guo Huang, Xuexi Zeng for the HPV genotyping assistance. We thank pathology department of Sichuan Provincial People's Hospital for their kind assistance in collecting data.

\section{Authors' contributions}

QL and JZ obtained funding and drafted the manuscript. JZ and JW designed the study and conducted the survey. JW, NJ and QW performed the analysis and interpreted the data. JZ and JW were the principal investigators, provided all facilities necessary to complete this work and were involved in editing the manuscript. All authors read and approved the final manuscript.

\section{Funding}

1. The Scientific research project of Sichuan provincial health and Family Planning Commission (18PJ115) provided ideas for the direction of the topic and help for quality assessment.

2. The National Nature Science Foundation of China (NCFS No. 81860469) provided help for data analysis and language modification of the manuscript.

\section{Availability of data and materials}

The datasets used and analyzed in this study are available from the corresponding author upon reasonable request.

Ethics approval and consent to participate

This study was approved by the Ethics Committee of Sichuan Provincial People's Hospital (NO.2019-323).

\section{Consent for publication}

Not applicable.

\section{Competing interests}

The authors declare that they have no competing interests.

\section{Author details}

${ }^{1}$ Departments of Cancer Research Laboratory, the Affiliated Hospital of Zunyi Medical University, No.149 Dalian Road, Zunyi 563003, Guizhou Province, China. ${ }^{2}$ Department of Laboratory Medicine, Sichuan Academy of Medical Sciences \& Sichuan Provincial People's Hospital, No. 32, West Second Section First Ring Rd., Chengdu 610072, Sichuan, China. ${ }^{3}$ School of Medicine, University of Electronic Science and Technology of China, No. 32, West Second Section First Ring Rd, Chengdu 610072, Sichuan, China.

Received: 23 February 2020 Accepted: 23 June 2020

Published online: 10 July 2020

\section{References}

1. Bray F, Ferlay J, Soerjomataram I, Siegel RL, Torre LA, Jemal A. Global cancer statistics 2018: GLOBOCAN estimates of incidence and mortality worldwide for 36 cancers in 185 countries. CA Cancer J Clin. 2018;68:394-424.

2. Chen W, Zheng R, Baade PD, Zhang S, Zeng H, Bray F, et al. Cancer statistics in China, 2015. CA Cancer J Clin. 2016;66:115-32.

3. Muñoz N, Bosch FX, de Sanjosé S, Herrero R, Castellsagué X, Shah KV, et al. Epidemiologic classification of human papillomavirus types associated with cervical cancer. N Engl J Med. 2003;348:518-27.

4. Liu Y, Li H, Pi R, Yang Y, Zhao X, Qi X. Current strategies against persistent human papillomavirus infection (review). Int J Oncol. 2019;55:570-84.

5. McClung NM, Lewis RM, Gargano JW, Querec T, Unger ER, Markowitz LE. Declines in Vaccine-Type Human Papillomavirus Prevalence in Females Across Racial/ Ethnic Groups: Data From a National Survey. J Adolesc Health. 2019:65:715-22.

6. Clifford GM, Gallus S, Herrero R, Muñoz N, Snijders PJF, Vaccarella S, et al. Worldwide distribution of human papillomavirus types in cytologically normal women in the International Agency for Research on Cancer HPV prevalence surveys: a pooled analysis. Lancet. 2005;366:991-8.

7. Feng Y, Peng Y, Zhu L, Niu X. Relationship of human papillomavirus subtypes and multiple infection with different cervical precancerous diseases in Sichuan Province. Sichuan Da Xue Xue Bao Yi Xue Ban. 2015;46: $422-5462$.

8. Chen Z, Wang Q, Ding X, Li Q, Zhong R, Ren H. Characteristics of HPV prevalence in Sichuan Province, China. Int J Gynaecol Obstet. 2015;131:277-80. 
9. He L, He J. Distribution of high-risk HPV types among women in Sichuan province, China: a cross-sectional study. BMC Infect Dis. 2019;19:390.

10. Long W, Yang Z, Li X, Chen M, Liu J, Zhang Y, et al. HPV-16, HPV-58, and HPV-33 are the most carcinogenic HPV genotypes in southwestern China and their viral loads are associated with severity of premalignant lesions in the cervix. Virol J. 2018;15:94

11. Zhu Y, Ding X, Wang Y, Gao J, Shen M, He J. Human papillomavirus infections in women with clinical gynaecological diseases in Southwest China. Int J STD AIDS. 2012;23:e1-5.

12. Li B, Wang H, Yang D, Ma J. Prevalence and distribution of cervical human papillomavirus genotypes in women with cytological results from Sichuan province, China. J Med Virol. 2019;91:139-45.

13. Chen Q, Xie L-X, Qing Z-R, Li L-J, Luo Z-Y, Lin M, et al. Epidemiologic characterization of human papillomavirus infection in rural Chaozhou, eastern Guangdong Province of China. PLoS One. 2012;7:e32149.

14. Lin M, Yang L-Y, Li L-J, Wu J-R, Peng Y-P, Luo Z-Y. Genital human papillomavirus screening by gene chip in Chinese women of Guangdong province. Aust N Z J Obstet Gynaecol. 2008;48:189-94.

15. Luo G, Sun X, Li M, Liu T, Hu G, He Y, et al. Cervical human papillomavirus among women in Guangdong, China 2008-2017: implication for screening and vaccination. J Med Virol. 2019;91:1856-65.

16. Jiang $L$, Tian X, Peng D, Zhang $L$, Xie F, Bi C, et al. HPV prevalence and genotype distribution among women in Shandong Province, China: analysis of 94,489 HPV genotyping results from Shandong's largest independent pathology laboratory. PLoS One. 2019;14:e0210311.

17. Wang J, Tang D, Wang K, Wang J, Zhang Z, Chen Y, et al. HPV genotype prevalence and distribution during 2009-2018 in Xinjiang, China: baseline surveys prior to mass HPV vaccination. BMC Womens Health. 2019;19:90.

18. Chen Z, Li Q, Huang Q, Liu H, Jiang H, Chen Z, et al. Characteristics of human papillomaviruses distribution in Guizhou Province, China. Virol J. 2019;16:123.

19. Li Z, Liu F, Cheng S, Shi L, Yan Z, Yang J, et al. Prevalence of HPV infection among 28,457 Chinese women in Yunnan Province, Southwest China. Sci Rep. 2016;6:21039.

20. Tang Y, Zheng L, Yang S, Li B, Su H, Zhang L-P. Epidemiology and genotype distribution of human papillomavirus (HPV) in Southwest China: a crosssectional five years study in non-vaccinated women. Virol J. 2017;14:84.

21. $\mathrm{Xu} \mathrm{HH}$, Lin A, Chen YH, Dong SS, Shi WW, Yu JZ, et al. Prevalence characteristics of cervical human papillomavirus (HPV) genotypes in the Taizhou area, China: a cross-sectional study of 37967 women from the general population. BMJ Open. 2017;7:e014135.

22. Xiang F, Guan Q, Liu X, Xiao H, Xia Q, Liu X, et al. Distribution characteristics of different human papillomavirus genotypes in women in Wuhan, China. J Clin Lab Anal. 2018:32:e22581.

23. Qian L, Zhang Y, Cui D, Lou B, Chen Y, Yu Y, et al. Analysis of epidemiological trends in human papillomavirus infection among gynaecological outpatients in Hangzhou, China, 2011-2015. BMC Infect Dis. 2017;17:393

24. Wu C, Zhu X, Kang Y, Cao Y, Lu P, Zhou W, et al. Epidemiology of Humanpapilloma virus infection among women in Fujian, China. BMC Public Health. 2017;18:95

25. Zhao F-H, Tiggelaar SM, Hu S-Y, Xu L-N, Hong Y, Niyazi M, et al. A multicenter survey of age of sexual debut and sexual behavior in Chinese women: suggestions for optimal age of human papillomavirus vaccination in China. Cancer Epidemiol. 2012;36:384-90.

26. Kim M-J, Kim JJ, Kim S. Type-specific prevalence of high-risk human papillomavirus by cervical cytology and age: data from the health checkups of 7,014 Korean women. Obstet Gynecol Sci. 2013;56:110-20.

27. Tao G, Yaling G, Zhan G, Pu L, Miao H. Human papillomavirus genotype distribution among HPV-positive women in Sichuan province, Southwest China. Arch Virol. 2018;163:65-72.

28. Li K, Yin R, Wang D, Li Q. Human papillomavirus subtypes distribution among 2309 cervical cancer patients in West China. Oncotarget. 2017;8: 28502-9.

29. Li J, Zhang D, Zhang Y, Wang X, Lin Y, Hu L. Prevalence and genotype distribution of human papillomavirus in women with cervical cancer or high-grade precancerous lesions in Chengdu, western China. Int J Gynaecol Obstet. 2011;112:131-4.
30. He J, He L. Knowledge of HPV and acceptability of HPV vaccine among women in western China: a cross-sectional survey. BMC Womens Health. 2018;18:130

\section{Publisher's Note}

Springer Nature remains neutral with regard to jurisdictional claims in published maps and institutional affiliations.
Ready to submit your research? Choose BMC and benefit from:

- fast, convenient online submission

- thorough peer review by experienced researchers in your field

- rapid publication on acceptance

- support for research data, including large and complex data types

- gold Open Access which fosters wider collaboration and increased citations

- maximum visibility for your research: over $100 \mathrm{M}$ website views per year

At $\mathrm{BMC}$, research is always in progress.

Learn more biomedcentral.com/submissions 